\section{Timetable for a reactor disaster begins to emerge}

THE Sovict report on the Chernobyl reactor accident, distributed to the Vienna delegations to the International Atomic Energy Agency last week, is said by those who have read it to be strong on details of the reactor design but thin on details of how the accident happened. But the sequence of events leading to the accident, and more details of the "unauthorized experiment "said to have been under way on 25-26 April, have emerged.

For the first time since the accident. there are suggestions in the Soviet document that the $\mathrm{RBMK}$ reactor design is not fault-free. Thus the report suggests that existing reactors of this type should be modified by means of longer control rods, 2.4 per cent uranium enrichment (now 2.0 per cent) and extra reactor sensors even if these measures "degrade the economics" of the reactor type.

The report is intended as the basis for a discussion of the accident to be held at Vienna next week. The confusion attending its appearance stems from what appears to have been a Soviet requirement that the agency itself should distribute the report to national delegations only, but allowing national delegations to deal with the document ( 382 pages of Russian text) as they see fit.

Other information about the content of the report has appeared in Sweden and from the Atomic Industrial Forum of the United States which on Monday this week released a brief summary of the sequence of events leading to the accident. The forum said that "at first glance the report appears to be complete and frank".

According to a report in the Japanese newspapers Asahi Shimbun the "experiment" was intended to determine the amount of energy that might be recovered from a spinning clectrical generating set and the coupled steam turbine after the steam input had been disconnected. According to this account, more than one assessment of this kind was planned, using the generating set at Chernobyl called Number 7 and for this reason, the reactor providing steam for the generator was not shut down. However, the system that would have caused the reactor to shut down of its own accord was disabled.

One of the difficultięs in reconstructing the course of events at Chernobyl reactor Number 4 appears to have been that the data-recording system used for monitoring normal operations had been switched to the monitoring of the electrical test, with the result that capacity for the recording of reactor data had been preempted.
As a consequence, the sequence of events has had to be inferred from a mathematical model of the reactor.

The sequence of events began roughly 24 hours before the first release of radioactivity, at 01:00 local time on 25 April, when steps were taken to reduce the operating power of the reactor. Twelve hours later, at 13.05, the Number 7 turbine generator was disconnected from the system, but its electrical output switched to turbine Number 8 . These are two generating sets handling the thermal outputs of the damaged reactor, Number 4 out of four completed reactors at the site.

The rate at which the speed of the Number 7 generating set would have declined would have been determined by the magnitude of the external electrical load. The emergency cooling system was disabled at 14.00 on 25 April, but the report says that the control room explicitly instructed that the reactor should continue to operate.

When instabilities appeared, two extra pumps were added to the water-cooling circuit some three and seven minutes respectively after 01.00 on 26 April, but the Soviet document says that the reactivity of the reactor had reached the point, at 01.22. at which the reactor should immediately have been shut down. In the

\section{Environmental research}

BRITISH scientists are hoping that a $£ 1$ million package of research projects can be put together to seize the scientific opportunities presented by the Chernobyl nuclear accident. Radionuclides were released into the atmosphere on a scale that would never be contemplated experimentally, giving a unique chance to study their pathways in the environment.

An expert committee organized by the Natural Environment Research Council, the Coordinating Group on Environmental Radioactivity, hopes to include researchers from government departments, the universities, the Central Electricity Generating Board, British Nuclear Fuels and the Meteorological Office in an integrated programme. Much of the information gained would be of direct benefit for it would aid understanding of the consequences of other accidental releases of radioactive material.

Studies carried out so far already reveal a few surprises. Radionuclides are much "stickier" than expected; once deposited event, the reports say, the operators persisted with their experiments on the turbines, including the closing of the stop control valve of turbine Number 8 four seconds after 01.23 on 26 April.

Within half a minute, the accounts continue, the reactor began to generate more power, and the operatives sought to close it down by means of the control rods. But in the event, the full entry of the rods was prevented by an explosion. A witness is reported as saying that he heard two loud explosions at that time and saw a fireball scattering sparks on the roof.

The Soviet report outlines a series of errors in safety procedures of which the reactor staff were guilty, including the disablement of all but six or eight of the control rods with which the reactor is equipped, and the disablement of the power control system that would normally maintain the power output near that for which the machine was designed. The result is that control of the reactor would have been more difficult. The decision to disable the automatic shut-down system for the reactor would have made it necessary to use manual procedures for controlling the power output in case of an emergency.

One of the puzzling features of the report is the statement that, after the explosions, the temperature of the uranium fuel increased to between 1,600 and 1,800 ${ }^{\circ} \mathrm{C}$, hot enough to volatilize some fission products but not enough to vapourize the refractory components of the fuel. But that step could be the one that apparently led to the further release of radioactivity on 29 April.

\title{
Making the most of Chernobyl
}

on vegetation they are not quickly washed into the soil. Thunderstorms, triggered as warm, moist air containing the plume of fall-out, prove to be particularly effective in washing radionuclides out of the atmosphere (see p.690 of this issue). These topics will be studied further: others needing attention are the overall pattern of deposition, which is highly heterogenous; the storage of radionuclides in snow and their release on melting; and whether the radionuclide pulse will confuse other studies on radionuclides in the environment.

Any programme would best be integrated with an overall European effort. Already attempts are under way for collaboration within the European Economic Community and it is possible that some money might be found from the European Commission. Otherwise national programmes will have to be tied together and funds for the British part must come from other programmes - there is little chance of extra money being granted in present political circumstances.

Alun Anderson 